\title{
Does Immigration Promote the Investment of the Monopolistic Firm?
}

\author{
Yasunori Fujita \\ Keio University, Tokyo, Japan \\ Email: yfujita@econ.keio.ac.jp
}

How to cite this paper: Fujita, Y. (2017) Does Immigration Promote the Investment of the Monopolistic Firm? Modern Economy, 8, 406-411.

https://doi.org/10.4236/me.2017.83030

Received: February 15, 2017

Accepted: March 18, 2017

Published: March 21, 2017

Copyright $\odot 2017$ by author and Scientific Research Publishing Inc. This work is licensed under the Creative Commons Attribution International License (CC BY 4.0).

http://creativecommons.org/licenses/by/4.0/

\begin{abstract}
In the present paper, we examine the effect of increasing uncertainty of immigrants' growth on the optimal timing of investment of a firm that has a monopolistic power over the labor market. It is revealed that when the uncertainty of immigrants' growth is more than a threshold level, increasing uncertainty of immigrants' growth accelerates the optimal timing of firms' investment and enhances the economic growth, even if the uncertainty of immigrants' growth is formulated by the geometric Brownian motion, which is in sharp contrast to the standard result that an increase in the uncertainty postpones the optimal timing.
\end{abstract}

\section{Keywords}

Optimal Stopping Theory, Geometric Brownian Motion, Value of Waiting, Immigrants, Monopolistic Power over Labor Market

\section{Introduction}

With an increase in the immigrants over the past ten years, workforces in the host countries have been growing significantly to the extent that the immigrants represent $70 \%$ of the increase in the workforce in Europe, and $47 \%$ in the United States as OECD [1] indicates. Although such increasing immigrants have been spurring interest in the relationship between the immigrants and the economic growth ([2] [3] and so on), few studies have tried to estimate the impact of migration on the economic growth, nor to conduct theoretical analyses by formulating economic models. The present study is an attempt to handle this situation by combining the optimal stopping theory with the market theory as in Fujita [4] [5] [6] and so on, to investigate the impact of the increase in the immigrants on investment of a monopolistic firm. More precisely, we construct a stochastic intertemporal model where the firm faces market uncertainty expressed by the 
geometric Brownian motion, to examine the effect of increasing uncertainty of immigrants' growth on the optimal timing of the investment, and hence the economic growth.

It is revealed that when the uncertainty of immigrants' growth is more than a threshold level, increasing uncertainty of immigrants' growth accelerates the optimal timing of the firm's investment, even if the uncertainty of immigrants' growth is formulated by the geometric Brownian motion, which is in sharp contrast to the standard result of McDonald and Siegel [7], Dixit and Pindyck [8] and so on, which shows an increase in the uncertainty postpones the optimal timing. Nishimura and Ozaki [9] and Trojanowska and Kort [10] also reversed the standard result, but by introducing the Knightian uncertainty, which is different from the present paper that assumes the geometric Brownian motion.

Structure of this paper is as follows. Section 2 formulates the objective function of the firm after constructing a basic model. Based on these analyses, in section 3 we reveal the effect of increasing uncertainty of immigrants' growth on the optimal timing of the investment, and hence the economic growth. Concluding remarks are made in section 4.

\section{Assumptions and Formulation of the Objective Function}

In order to investigate the effect of growing number of immigrants on the economic growth, let us consider a stochastic intertemporal economy with one firm that has monopolistic power over the labor market. To contemplate when to conduct investmentby incurring the cost of $K$ to create a new product. For the simplicity of the analysis, we assume that the product is made only by the labor and the product price is constant at $p$. We also assume that the time passes continuously with importance of the future diminishing with the discount rate of $\rho$.

Letting $x(t)$ denote the firm's output in period $t$ and specifying one unit of production requires one unit of labor, we assume the wage in period $t, w(t)$, is expressed by the following linear inverse labor supply function, $w(t)=c(t) x(t)$, where $c(t)$ is a positive variable that represents the size of the labor market, which is positively related to the amount of the immigrants, in period $t$, and fluctuates stochastically according as the following geometric Brownian motion as in Fujita (2016),

$$
\frac{d c}{c(t)}=s d z
$$

with initial value $c_{0}$, where $s$ is a positive constant that expresses the labor market volatility in a sense that larger $s$ means more uncertainty of the labor market, while $d z$ is Wiener process that expresses the random movement. Then, the firm's profit in period $t, \pi(t)$, is described as $\pi(t)=(p-c(t) x(t)) x(t)$, so that, we have the firm's first order condition for the profit maximization as $\frac{\partial \pi}{\partial x}=p-2 c(t) x(t)=0$, to yield the firm's output, and hence the profit, in the equilibrium in period $t$ as $x(t)=\frac{p}{2 c(t)}$ and $\pi(t)=\frac{p^{2}}{4 c(t)}$, respectively.

Since we have the first and the second derivatives of the profit as 
$\frac{d \pi}{d c}=-\frac{p^{2}}{4 c(t)^{2}}$ and $\frac{d^{2} \pi}{d c^{2}}=\frac{p^{2}}{8 c(t)^{3}}$ respectively, we can express the stochastic process of the firm's profit, by making use of Equation (1) and Ito's lemma, as

$$
\frac{d \pi}{\pi}=\mu d t+\sigma d z
$$

with initial value $\pi_{0}=\frac{p^{2}}{4 c_{0}}$, where $\mu=\frac{s^{2}}{4}$ and $\sigma=-s$.

Now, by making use of this stochastic process of the firm's profit, we are ready to express the firm's objective function to maximize in period 0 , $V=E\left[\int_{t^{*}}^{\infty} \mathrm{e}^{-\rho t} \pi(t) \mathrm{d} t-\mathrm{e}^{-\rho t^{*}} K\right]$, as a function of $c^{*}$, the market size $c$ in period $t^{*}$ when the firm's investment is carried out. For this purpose, if we let $G\left(\pi_{0}\right)$ denote the expected value of one unit of the firm's profit in period $t^{*}$ (i.e., the expected value of $-\mathrm{e}^{-\rho t^{*}}$ ) as a function of the initial profit $\pi_{0}$, the general solution to $G\left(\pi_{0}\right)$ is expressed as

$$
G\left(\pi_{0}\right)=\alpha\left(\pi_{0}\right)^{\gamma_{1}}+\beta\left(\pi_{0}\right)^{\gamma_{2}}
$$

where $\gamma_{1}<0$ and $\gamma_{2}>0$ are solutions to the characteristic Equation $\frac{\sigma^{2}}{2} x(x-1)-\mu x-\rho=0$, which is rewritten as $x(2 x-3)-\frac{4 \rho}{s^{2}}=0$ by substituting $\mu=\frac{s^{2}}{4}$ and $\sigma=-s$ into it. If we let $\pi^{*}$ denote the firm's profit in period $t^{*}$, it follows that $\alpha=0$ and $\beta=\left(\frac{1}{\pi^{*}}\right)^{\gamma_{2}}$ since $G\left(\pi_{0}\right)$ satisfies $G(\infty)=0$ and $G\left(\pi^{*}\right)=1$

Therefore, we obtain $G\left(\pi_{0}\right)=\left(\frac{\pi_{0}}{\pi^{*}}\right)^{\gamma}$, where

$$
\gamma=\frac{3+\sqrt{9+\frac{32 \rho}{s^{2}}}}{4}
$$

by substituting $\alpha=0$ and $\beta=\left(\frac{1}{\pi^{*}}\right)^{\gamma_{2}}$ into Equation (3) and letting $\gamma$ denote $\gamma_{2}$.

Thus, we can derive the firm's objective function to maximize in period $0, V$, as $V=\left(\frac{\pi_{0}}{\pi^{*}}\right)^{\gamma}\left(\frac{\pi^{*}}{\rho-s^{2}}-K\right)$, which is rewritten as

$$
V=\left(\frac{b^{*}}{b_{0}}\right)^{\frac{3+\sqrt{9+\frac{32 \rho}{s^{2}}}}{4}}\left(\frac{1}{\rho-s^{2}} \frac{p^{2}}{4 b^{*}}-K\right)
$$

by substituting $\pi_{0}=\frac{p^{2}}{4 c_{0}}, \pi *=\frac{p^{2}}{4 c^{*}}$ and Equation (4) into $V=\left(\frac{\pi_{0}}{\pi^{*}}\right)^{\gamma}\left(\frac{\pi^{*}}{\rho-s^{2}}-K\right)$

\section{Optimal Timing of the Investment}

Now, we can determine the firm's optimal timing of the investment, to examine 
the effect of increased uncertainty caused by the growing number of the immigrants on the economic growth. Standard theory of the optimal timing of investment generally tells us that an increase in the uncertainty pulls up the value of waiting to postpone the optimal timing, which leads to the slowdown of the economic growth. The purpose of the paper is to investigate if this standard result holds if we construct a specific model to formulate the stochastic fluctuation of the wage rate.

Since the model of the present paper is stochastic, the optimal timing is expressed by the cut off level of the market size $c^{*}$. Therefore, by differentiating Equation (5) with respect to $c^{\star}$ and setting it to zero, we have the optimal cut off level of the market size $c^{*}$ for the firm as

$$
c^{*}=\frac{\left(-3 s+\sqrt{9 s^{2}+32 \rho}\right)^{2} p^{2}}{32^{2} \rho^{2}\left(\rho-s^{2}\right) K}
$$

Graph of $c^{\star}$ is depicted as a U-shaped curve with its minimum point at $\hat{s}$ on the $s$ - $c^{*}$ space as in Figure 1, which is in sharp contrast with the standard result of the value of waiting where $c^{\star}$ decreases monotonically as $s$ increases. To be exact, by differentiating Equation (6) with respect to $s$ and setting it to zero, we have the threshold level of the market uncertainty $\hat{s}$, so as to satisfy

$$
3=\frac{s \sqrt{9 s^{2}+32 \rho}}{\rho-s^{2}}
$$

The graph of the left hand side of (7) is drawn as a horizontal line, while the graph of the right hand side of (7) is drawn as a monotonically upward curve that starts from the origin and goes infinity when $s=\sqrt{\rho}$. Therefore, $\hat{s}$ is determined uniquely as in Figure 2.

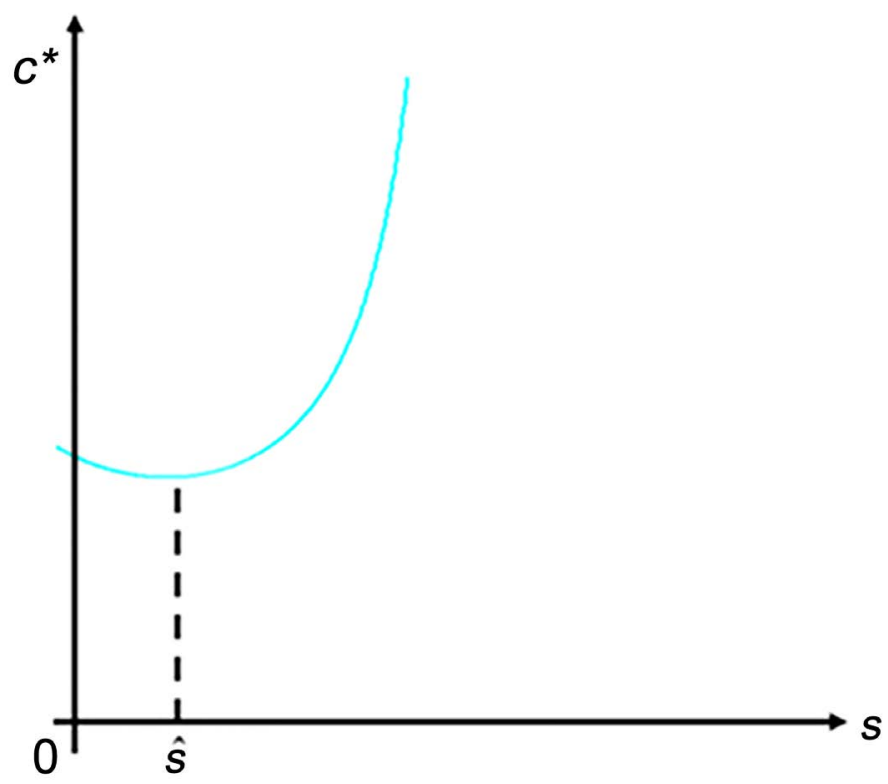

Figure 1. Increase in the number of immigrants and the timing of investment. 


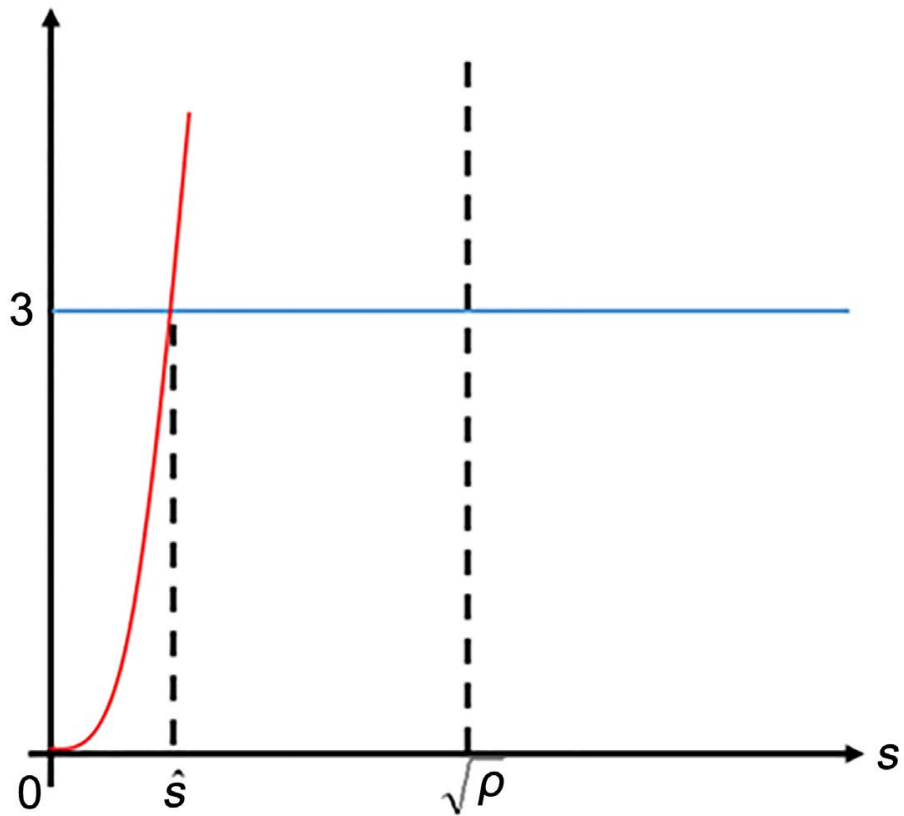

Figure 2. Determination of the threshold level of $s$.

Since large $s$ means increasing uncertainty of immigrants' growth and small (large) $c^{\star}$ means postponement (acceleration) of the investment, we have the following proposition.

Proposition: (1) If uncertainty of immigrants' growth is less than a threshold level, increasing uncertainty of immigrants' growth postpones the optimal timing of the firm's investment; (2) if uncertainty of immigrants' growth is more than a threshold level, however, increasing uncertainty of immigrants' growth accelerates the optimal timing of the firm's investment.

We can conclude from Proposition (2) that when the uncertainty caused by the growing number of immigrants is more than the threshold level $\hat{s}$, an increase in the uncertainty of immigrants' growth accelerates the optimal timing and enhances the economic growth, which is in sharp contrast to the standard result of the theory of the optimal timing of investment.

In the present model, as Equation (2) shows, increasing uncertainty of immigrants' growth pulls up the growth rate of the firm's profit, which results in accelerating the timing of the investment. If this accelerating effect surpasses the standard postponing effect, overall effect accelerates the timing of the investment. Proposition (2) demonstrates that such a case prevails if uncertainty of immigrants' growth is more than the threshold level $\hat{s}$.

\section{Conclusions}

In the present paper, we attempted to investigate the effect of increased uncertainty caused by the growing number of immigrants on the economic growth by combining the optimal stopping theory with the standard market theory. Our result is: When the uncertainty of immigrants' growth is more than a threshold level, increasing uncertainty of immigrants' growth accelerates the optimal tim- 
ing of firms' investment and enhances the economic growth, even if we formulate the immigrants' uncertainty by the geometric Brownian motion, not by the Knightian uncertainty.

In order to derive explicit results, we made several simplifying assumptions. Thus, it is necessary to lay out a general framework by relaxing those assumptions to examine the robustness of the results of the present paper. We also need to give an empirical testing of this model, in order to contribute to the advancement of the monopolistic theory as well as the optimal stopping theory. These are issues which are left for our future research.

\section{References}

[1] OECD (2012) Renewing the Skills of Ageing Workforces: The Role of Migration, International Migration Outlook 2012. OECD Publishing, Paris.

[2] Gagnon, J. (2014) Demographic Change and the Future of the Labour Force in the EU27, in other OECD Countries and Selected Large Emerging Economies. Matching Economic Migration with Labour Market Needs, OECD Publishing, Paris, 3765.

[3] Hunt, J. (2010) Skilled Immigrants' Contribution to Innovation and Entrepreneurship in the US. Open for Business: Migrant Entrepreneurship in OECD Countries, OECD Publishing, Paris, 257-272.

[4] Fujita, Y. (2007) Toward a New Modeling of International Economics: An Attempt to Reformulate an International Trade Model Based on Real Option Theory. Physica A: Statistical Mechanics and its Applications, 383, 507-512. https://doi.org/10.1016/j.physa.2007.04.041

[5] Fujita, Y. (2008) Competition and Welfare for a Stochastically Fluctuating Market with Irreversible Decisions. Physica A: Statistical Mechanics and its Applications, 387, 2846-2850. https://doi.org/10.1016/j.physa.2008.01.004

[6] Fujita, Y. (2016) Optimal Amount and Timing of Investment in a Stochastic Dynamic Cournot Competition. Theoretical Economics Letters, 6, 1-6. https://doi.org/10.4236/tel.2016.61001

[7] McDonald, R. and Siegel, D. (1986) The Value of Waiting to Invest, The Quarterly Journal of Economics, 101, 707-727. https://doi.org/10.2307/1884175

[8] Dixit, A.K. and Pindyck, R.S. (1994) Investment under Uncertainty. Princeton University Press, Princeton.

[9] Nishimura, K. and Ozaki, H. (2007) Irreversible Investment and Knightian Uncertainty. Journal of Economic Theory, 136, 668-694. https://doi.org/10.1016/j.jet.2006.10.011

[10] Trojanowska, M. and Kort, P. (2010) The Worst Case for Real Options. Journal of Optimization. Theory and Applications, 146, 709-734.

https://doi.org/10.1007/s10957-010-9687-0 
Submit or recommend next manuscript to SCIRP and we will provide best service for you:

Accepting pre-submission inquiries through Email, Facebook, LinkedIn, Twitter, etc. A wide selection of journals (inclusive of 9 subjects, more than 200 journals)

Providing 24-hour high-quality service

User-friendly online submission system

Fair and swift peer-review system

Efficient typesetting and proofreading procedure

Display of the result of downloads and visits, as well as the number of cited articles Maximum dissemination of your research work

Submit your manuscript at: http://papersubmission.scirp.org/

Or contact me@scirp.org 